\title{
A Putative Adverse Outcome Pathway Relevant to Carcinogenicity Induced by Sulfuric Acid in Strong Inorganic Acid Mists
}

REVIEW

\author{
Jun Hyuek Yang ${ }^{1, *}$, Preeyaporn Koedrith ${ }^{2, *}$, Doo Seok Kang ${ }^{1, *}$, Nam Kook Kee ${ }^{1}$, Jong-Hyeon Jung ${ }^{3}$, Cheol Min Lee ${ }^{4}$, \\ Yeon-Soon Ahn ${ }^{5}$, Young Rok Seo ${ }^{1}$
}

${ }^{1}$ Department of Life Science, Dongguk University Biomedi Campus, Goyang, Korea, ${ }^{2}$ Faculty of Environment and Resource Studies, Mahidol University, NakhonPathom, Thailand, ${ }^{3}$ Faculty of Health Science, Daegu Haany University, Gyeongsan, ${ }^{4}$ Department of Chemical and Biological Engineering, College of Natural Science and Engineering, Seokyeong University, Seoul, ${ }^{5}$ Department of Preventive Medicine and Institute of Occupational and Environmental Medicine, Yonsei University Wonju College of Medicine, Wonju, Korea

\begin{abstract}
Based on epidemiological studies, an International Agency for Research on Cancer Working Group determined that strong inorganic acid mists containing sulfuric acid are carcinogenic to human even though, sulfuric acid, per se, is not. Accumulative studies indicate that there is a link between chronic occupational exposure to sulfuric acid mists and an increased risk of laryngeal cancer. Unintended, acute exposure to sulfuric acid mists can cause corrosive damage to target tissues depending on the route of exposure. This review compares the toxicity and carcinogenicity of sulfuric acid mists compared to other strong inorganic acid mists. It also examines the routes and duration of exposure (short-term, prolonged, and long-term). In vivo evidence does not support or refute the carcinogenicity of sulfuric inorganic mists even though its co-carcinogenic or promoting potential has been considered. On the basis of existing evidence on sulfuric acid mist toxicity, we suggested a putative adverse outcome pathway (AOP) relevant to carcinogenicity caused by mists containing sulfuric acid. A possible key factor involved in sulfuric acid mist carcinogenesis is the genotoxic effects of low pH since it can increase instability in chromosomes and DNA. A putative AOP for sulfuric acid mist carcinogenicity would help generate better risk assessments and more accurate predictions regarding the risk of developing cancer due to prolonged exposure. Establishing an AOP would also be useful for future studies examining the carcinogenicity of other strong inorganic mists.
\end{abstract}

(J Cancer Prev 2019;24:139-145)

Key Words: Sulfuric acids, Adverse outcome pathways, Chemical accidents, Carcinogenesis

\section{INTRODUCTION}

The evolution of the chemical industry has led to the use of a wide variety of chemicals, including acid in the forms of mist, vapor, and gas. Workers are frequently exposed to these forms of acid during manufacturing processes [1]. Liquid sulfuric acid is commonly prepared in mist form (commonly referred to as a liquid aerosol) due to its low volatility and its affinity for water. This form of sulfuric acid can release sulfur trioxide vapors, especially at high concentrations and temperatures without atmospheric moisture. The highest levels of sulfuric acid mist exposure occur during metal pickling, sulfuric acid production, and isopropanol production. Moderate levels of exposure occur during soap, detergent, nitric acid, and ethanol production. Low levels of exposure occur during copper refining, zinc refining, phosphate fertilizer production and lead battery production [2].

Strong inorganic acid mists are hazardous substances that can cause severe skin burns and eye damage. Among these mists, those that contain sulfuric acid are classified as group 1 carcinogens and are deemed carcinogenic to humans by the

Received December 31, 2018, Revised September 14, 2019, Accepted September 17, 2019

Correspondence to: Young Rok Seo

E-mail: seoyr@dongguk.edu, ORCID: Young Rok Seo, https://orcid.org/0000-0002-4093-4073

*These authors contributed equally as the co-first author.

Copyright (C) 2019 Korean Society of Cancer Prevention

(c) This is an Open Access article distributed under the terms of the Creative Commons Attribution Non-Commercial License (http://creativecommons.org/licenses/by-nc/4.0) which permits unrestricted non-commercial use, distribution, and reproduction in any medium, provided the original work is properly cited. 
International Agency for Research on Cancer (IARC) [3]. Chronic exposure to low levels of sulfuric acid mists are difficult to perceive and may go unnoticed. Sulfuric acid mists generated from chemical incidents can contain high levels of sulfuric acid at the accident site, and they typically react with other materials and cause corrosion. Even though international regulations are established, chemical accidents causing exposure to sulfuric acid mists still occur due to natural disasters or poor workplace management. For instance, sulfuric acid leakages occurred in the Kyungbuk province of the Republic of Korea in 2018 and at Oberhausen, Germany in 2017. A zinc sulfuric acid leak occurred at Ulsan in the Republic of Korea in 2016, and a sulfuric acid spill occurred in Kansas City, Missouri, USA in 2016 [4-7]. After an accident with sulfuric acid mists, environmental exposure is estimated using diverse scenarios from a chemical fate model, which is used to determine chemical persistence [8]. Victims in and around the chemical accident site mainly suffer acute exposure to sulfuric acid mists, whereas workers in workplaces and people living near the accident site are chronically exposed. Therefore, risk assessments are necessary for both acute and chronic exposure to sulfuric acid mists to adequately address the health risks of exposed workers and/or chemical accident victims.

Recently, adverse outcome pathway (AOP) has emerged as an important tool for assessing risk. An AOP is a conceptual framework that describes a molecular initiating event (MIE) and sequential key events (KE) at different biological levels (cell, tissue, and organ) for the purpose of assessing ecotoxicological effects or adverse outcomes (AO) at individual or population levels. This biological map represents an interconnected series of events and chemical toxicity mechanisms to support human health or ecological risk assessments based on the weight of evidence [9]. Since AOP is not a chemical-specific approach, it can be applied to a wide variety of stressors [10]. Previous studies on potential carcinogen related AOPs have been established, but AOP studies with regard to the carcinogenicity of sulfuric acid mists are still not completely understood.

In this review, we describe the major toxicological effects of sulfuric acid mists and compare them to other strong inorganic acid mists. We also discuss their potential routes and durations of exposure (short-term, prolonged, and long-term). Furthermore, we suggest a putative AOP related to the carcinogenicity caused by sulfuric acid in strong inorganic acid mists using chronic and acute exposure in occupational and chemical accident scenarios, respectively.

\section{COMPARING THE CARCINOGENICITY OF SULFURIC ACID MISTS AND OTHER STRONG INORGANIC ACID MISTS}

According to the IARC monograph, sulfuric acid is the most widely used strong inorganic acid, and the deleterious effects of sulfuric acid mists and other inorganic acid mists (those containing hydrochloric, nitric, hydrofluoric, and phosphoric acids) have been studied extensively. Previous reports have linked sulfuric acid mist exposure with an increased risk of respiratory cancer (e.g., laryngeal and lung cancer) in exposed workers [1]. For this reason, the use of sulfuric acid has decreased, and it has been replaced with alternative inorganic acids like hydrochloric acid [3]. Even though strong hydrochloric acid is toxic to humans (e.g., it is corrosive to the eyes, skin, and mucous membranes), it is not classified as a carcinogen by the IARC or the United States Environmental Protection Agency. Consistent with this classification, one case-control study of hydrogen chloride revealed that it was not able to cause lung cancer [11]. Nevertheless, detailed studies examining the carcinogenicity of inorganic acid mists, including sulfuric acid and other strong inorganic acids, are still needed to provide confirmation.

Sulfuric acid mist is categorized as a group 1 carcinogen by the IARC, but sulfuric acid, itself, is not [3]. The carcinogenicity of sulfuric acid mists have been confirmed in chronically exposed rats and mice [12,13], however, no evidence linking sulfuric acid (per se) exposure to cancer has been reported by the Agency for Toxic Substances and Disease Registry [14]. Epidemiological and cohort studies have shown sulfuric acid mists induce carcinogenicity, but in vivo evidence is inadequate and controversial. For instance, a previous study of sulfuric acid-based isopropanol production revealed that US workers had an increased prevalence of nasal sinus cancer. A cohort study examining the steel pickling process, which uses sulfuric acid, found that Swedish workers had an increased prevalence of laryngeal cancer. A nested case-control study involving a petrochemical plant that was using sulfuric acid showed that the risk of acquiring laryngeal cancer in US workers was excessive. Together, these studies reveal an increase in the incidences of cancer in humans and positive exposure-response relationships when sulfuric acid mists are the most common exposure [1]. Although a carcinogenic mechanism of inorganic acid mist has not been identified, complementary evidence points to low $\mathrm{pH}$ as the common causative factor. Low $\mathrm{pH}$ can cause genetic damage, and an acidic cellular microenvironment can induce DNA damage and repair $[13,15]$. 


\section{POTENTIAL EXPOSURE TO SULFURIC ACID MISTS IN OCCUPATIONAL ENVIRONMENTS AND DURING CHEMICAL ACCIDENTS}

People can be exposed to chemicals under various circumstances including in occupational environments and accidents (Fig. 1). Occupational exposures are often dependent on process control measures (e.g., ventilation and containment) and the distance of a worker from the emission source of sulfuric acid mists. Sulfuric acid is the one of commonly used strong inorganic acids in various industries. Although safety regulations and guidelines are in place to limit exposure to sulfuric acid in a work environment, long-term occupational exposure still occurs. Previous epidemiological and cohort studies have revealed an association between chronically inhaled sulfuric acid mists and respiratory tract cancer in workers [2]. In this respect, inhalation is recognized as a potential route of exposure for sulfuric acid mists in the workplace since they can readily disperse throughout airways. Not only the analytical procedure but also the sampling method may affect the determination of aerosol-like sulfuric acid forms in the work area. Thus, the results can be different depending on the sampler and sampling head being used. Moreover, conventional sampling techniques cannot determine the distribution of particle sizes of the acid mists or distinguish between their liquid and gaseous phases. Therefore, the number of measurements related to aerosolized sulfuric acid in the workplace is limited $[1,16]$.

During accidents involving large amounts of sulfuric acid, a visible mist cloud containing a significant level of sulfuric acid is produced when the acid comes in contact with air [7]. A mist cloud with such a high level of sulfuric acid would result in high levels of exposure to surrounding locations and neighborhoods. In such a situation, skin contact and inhalation are considered potential routes for short-term and/or repetitive prolonged exposure. The effects of sulfuric acid on the skin are well known and caused by its acidity or low $\mathrm{pH}$. They include severe burns, dermatitis, skin corrosion, blisters, redness, and so on [17]. However, less obvious injuries to the respiratory system can manifest long after the chemical accident is contained. Furthermore, response efforts to sulfuric acid accidents are primarily focused on containment and cleanup of the bulk spill. But chemical accidents (e.g., by leakage, fire, or explosion) that generate acid mists can contain complex mixtures of various chemicals that can contaminate air or waterways, which can eventually lead to chronic adverse effects on human health [18].

Figure 2 is a fate model illustrating the major routes of exposure for sulfuric acid mists generated by chemical accidents. It shows that sulfuric acid mists might be dispersed by wind or by waterways after they are dissolved in water. For this reason, the concentration of sulfuric acid mists tends to decrease over time. Based on chemical incident management guidelines, a chemical decontamination response is initiated to terminate or mitigate the loss of containment and limit adverse health effects. One of the primary concerns of this response is the repeated and prolonged exposure via inhalation that can occur in victims during the response period. Although the short-term treatment

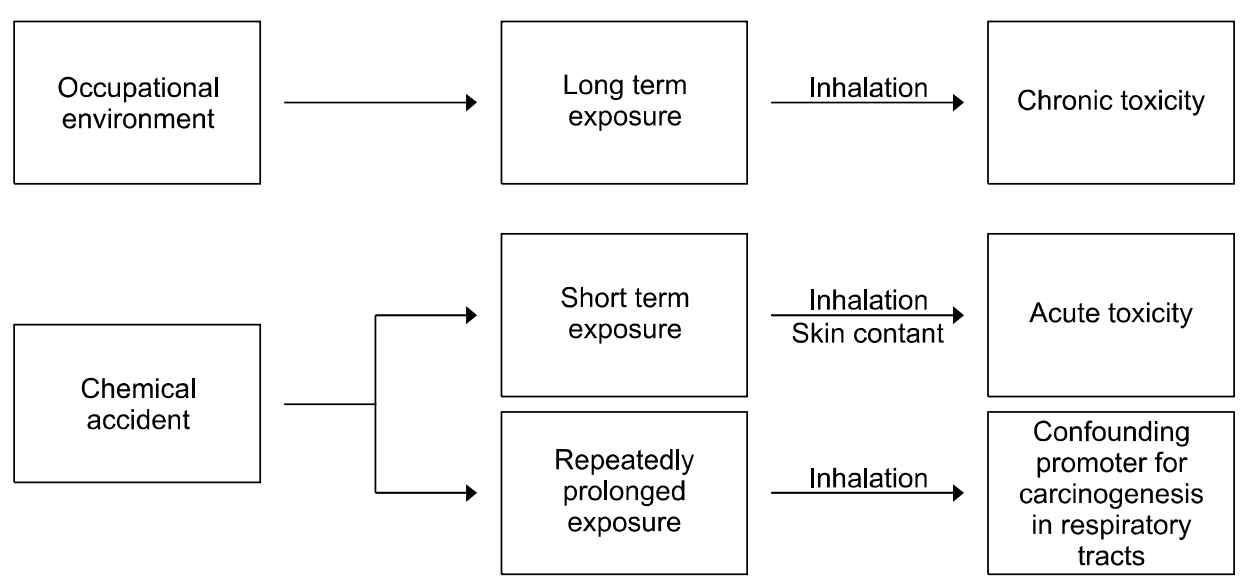

Figure 1. A diagram showing the overall toxicity and major routes of chronic and acute exposure to sulfuric acid mists caused by workplace environments and chemical accidents. In occupational environments, inhalation is a potential route of exposure since mist display gaseous characteristics and are widely dispersed throughout respiratory airways. During chemical accidents, skin contact and inhalation are potential routes for short-term and/or repetitive prolonged exposure. Once sulfuric acid mists come in contact with air, it may persist in nearby locations and neighborhoods causing prolonged exposure. Therefore, sulfuric acid mists are regarded as confounding promoters for the induction of respiratory tract cancers. 


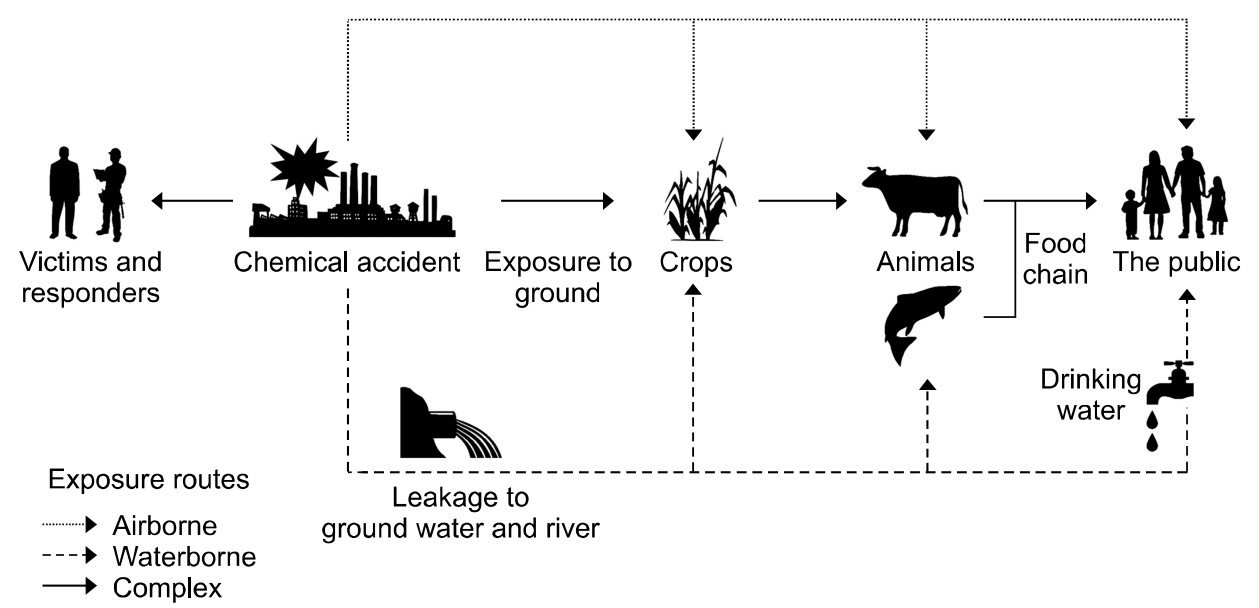

Figure 2. A schematic diagram illustrating the potential pathways of exposure for sulfuric acid mists in caused by a chemical accident. A fate model represents the major pathways of exposure during accidents with sulfuric acid mists that can be dispersed when they come in contact with air or waterways. After an incident occurs, a response is launched to decontaminate and mitigate adverse health effects, but there is still a risk of repeated and prolonged exposure for responders, victims, and the general public due to airborne and waterborne contamination.

for acute exposure to sulfuric acid mists is effective, long-term treatment of complex and chronic symptoms is still lacking because they are difficult to investigate.

Therefore, understanding the chronic adverse effects caused by exposure to sulfuric acid mists in both the workplace and/or after an accident is necessary to conduct an accurate risk assessment and reduce toxicity. After chronic exposure, an investigation of key molecular events at different biological levels and adverse effects through a putative AOP would provide better insight into the biological interference of and the cancer risks related to sulfuric acid mists.

\section{CURRENT EVIDENCE RELATED TO SULFURIC ACID MIST-INDUCED TOXICITY AND A PUTATIVE ADVERSE OUTCOME PATHWAY RELATED TO ITS CARCINOGENICITY}

An AOP framework begins as a MIE, which leads to an AO through KEs at various biological levels, and these components are connected by KE relationships [19]. In the case of exposure to sulfuric acid mist, sulfate and/or hydrogen ions are dissociated in aqueous solvent or humidified environment because of its strong acidic characteristics [14]. Therefore, the toxicological effects of sulfuric acid mists are dependent on the effects of its associated sulfate and/or hydrogen ions.

Figure 3 demonstrated the putative AOP with respect to sulfuric acid mist carcinogenicity. As the MIE, sulfate and/or hydrogen ions in sulfuric acid mists are absorbed by the mucous membranes of the respiratory system and deposited in the upper airways. After deposition, cations (hydrogen ions, $\mathrm{H}^{+}$) enter the bloodstream while dissociated anions (sulfate ions, $\mathrm{SO}_{4}{ }^{-2}$ ) enter the body's electrolyte pool [20]. Consequently, the localized reduction of $\mathrm{pH}$ triggered by the elevated levels of hydrogen ions causes more damage than the acute or chronic exposure to the sulfate ions [14].

Generally, intracellular $\mathrm{pH}$ is regulated by homeostatic transport systems [21]. Changes in protein crystallinity by low intracellular $\mathrm{pH}$ can affect molecular diffusion rates through membranes and enable encapsulation and release of molecules within the membrane [22,23]. A significant decrease in extracellular $\mathrm{pH}$ can induce crystalline polymorphism of ionic amphiphiles and proteins within the self-buffering system [22]. An extremely low $\mathrm{pH}$ caused by acute exposure to sulfuric acid mists can cause adverse effects because the buffering capacity is disturbed, and, consequently, cytoplasmic $\mathrm{pH}$ may not recover to normal levels [24]. At the tissue level, the corrosiveness of strong acids results in increased mucus viscosity, delayed mucociliary clearance, increased airway resistance, impaired gas exchange, and suppressed macrophage functions $[14,25,26]$. Moreover, strong acids can cause rapid coagulation and necrosis by denaturing proteins in skin tissues [27]. Many case studies have thoroughly described adverse symptoms associated with strong acid exposure. They include severe burns, pain, dermatitis, skin corrosion, blisters, and redness [28]. Excessive sulfuric acid exposure can lead to death when more than $50 \%$ of the body's 


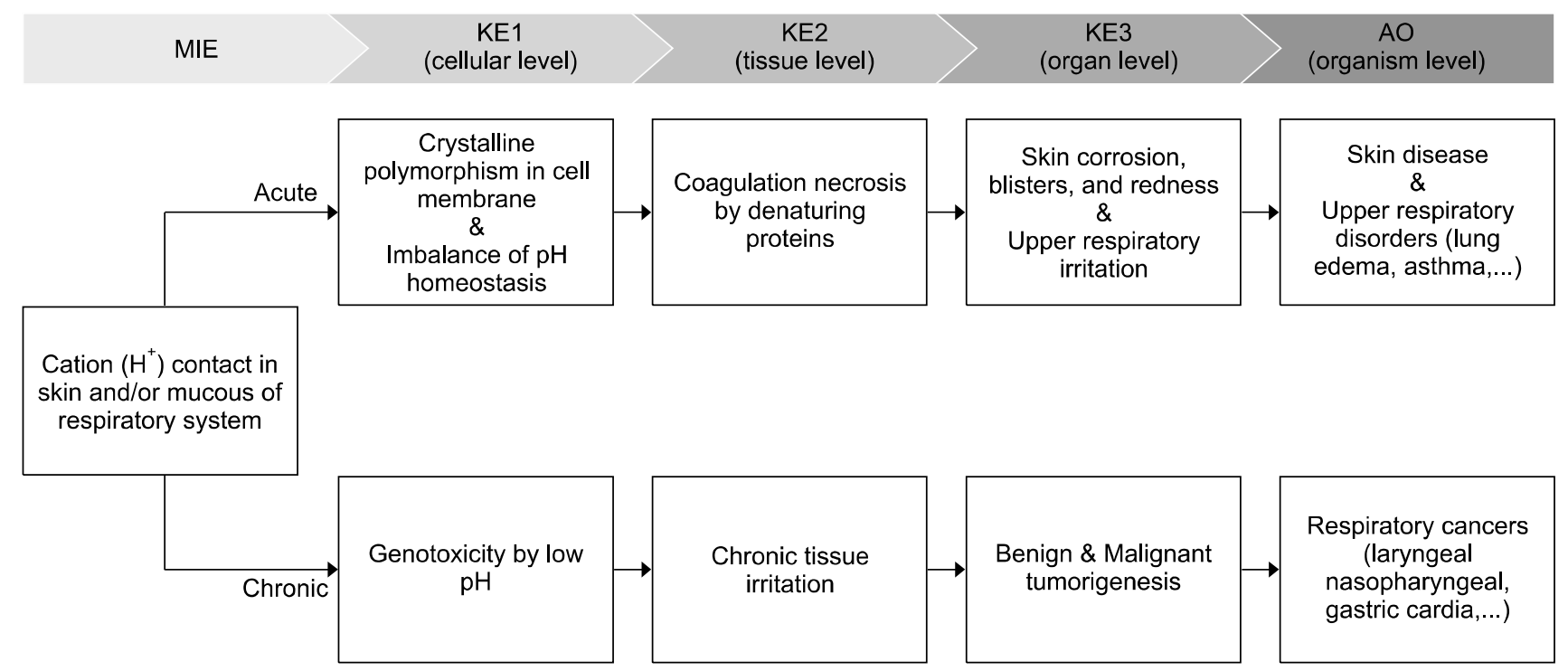

Figure 3. A putative adverse outcome (AO) pathway (AOP) related to sulfuric acid mists carcinogenicity. Upper panel: An AOP framework that consists of a molecular initiating event (MIE) leading to an adverse outcome through the key events (KEs) at various biological levels (ranging from cells to organ systems) and these KE relationships. Lower panel: The MIE cause a low $\mathrm{pH}$, which can result in acute or chronic abnormal biological states. Based on the putative AOP, a possible mechanism of genetic instability relates to low pH, which can induce tumorigenesis or carcinogenesis.

surface area is exposed [29-31].

Chronic exposure to sulfuric acid mist induces genotoxicity according to some studies [32-34]. Chronic inflammation results in the release of free radicals, which have a genotoxic action [35]. The promotion of carcinogenesis by sulfuric acid exposure has been postulated by inducing chronic tissue irritation [34]. Since genomic instability caused by genotoxic agents is a prerequisite for tumorigenesis [36], the genotoxic effects of low $\mathrm{pH}$ attributed to sulfuric acid mists could result in respiratory tumors [37]. Exposure to sulfuric acid mists is associated with nasopharyngeal and gastric cardia cancers [37-39]. Based on the putative AOP, a plausible mechanism of sulfuric acid mist carcinogenicity could relate to the genetic damage caused by low $\mathrm{pH}$, which includes chromosomal aberrations as well as depurination or deamination of cytidine in DNA.

\section{CONCLUSION}

Strong inorganic mists containing sulfuric acid are regarded as a human carcinogen and or a carcinogenetic promoter by the IARC. In this review, we described current studies comparing the carcinogenicity of sulfuric acid mists to other strong inorganic acid mists. We also discussed the potential pathways of exposure to sulfuric acid mists caused by chemical accidents and occupational environments. Evidence that chronic exposure to sulfuric acid mists has toxicological effects that can lead to cancer is still sparse. Also, there is little information in the AOP knowledge database (KB) related to strong inorganic acid mist carcinogenicity. Herein, we attempted to establish a putative AOP related to sulfuric acid mist toxicity, which reflects KEs and AOs at different biological levels (ranging from macromolecules to organ systems), and their relationships. Low $\mathrm{pH}$ may contribute to the carcinogenic potential of sulfuric acid mists upon prolonged exposure. Establishing a putative AOP would be an effective approach at accurately predicting AOs based on carcinogenic risk and preventing cancer caused by prolonged occupational or accidental chemical exposure. In combination with a big data-based molecular networks with scientific verification, this approach would increase the reliability of existing AOP KB and risk assessments relative to strong inorganic acids mists.

\section{ACKNOWLEDGMENTS}

This study was supported by a grant (2017001970001) from the Korea Ministry of Environment through "Development of assessment technology for human health impact after chemical accident".

\section{CONFLICTS OF INTEREST}

No potential conflicts of interest were disclosed. 


\section{REFERENCES}

1. International Agency for Research on Cancer (IARC). Chemical agents and related occupations. IARC Monogr Eval Carcinog Risks Hum 2012;100:9-562.

2. Sathiakumar N, Delzell E, Amoateng-Adjepong Y, Larson R, Cole P. Epidemiologic evidence on the relationship between mists containing sulfuric acid and respiratory tract cancer. Crit Rev Toxicol 1997;27:233-51.

3. Occupational exposures to mists and vapours from strong inorganic acids and other industrial chemicals. Working Group views and expert opinions, Lyon, 15-22 October 1991. IARC Monogr Eval Carcinog Risks Hum 1992;54:1-310.

4. Vaaju. Gyeongbuk Chilgok army waste treatment company- no loss of life. https://vaaju.com/koreaeng/\%EC\%A2\%85\%ED\%95\%A9gyeongbuk-chilgok-army-waste-treatment-company-no-loss-oflife. Accessed September 1, 2019.

5. Mirror. Sulphuric acid cloud from chemical plant accident triggers evacuations as 150 residents suffer breathing problems. https://www.mirror.co.uk/news/world-news/sulfuric-acid-cloudchemical-plant-9831312. Accessed September 1, 2019.

6. Knowledge for the Sulphuric Acid Industry. Sulphuric acid plant safety - accidents (recent). http://www.sulphuric-acid.com/techmanual/ plant_safety/safety_accidents.htm. Accessed September 1, 2019.

7. Reuters. More than 100 treated after chemical accident in northeastern Kansas. https://www.reuters.com/article/us-kansas-chemicalspill-idUSKCN12L1ZG. Accessed September 1, 2019.

8. Pennington DW, Ralston M. Multimedia persistence and EPAs Waste Minimization Prioritization Tool, SETAC news. http://www. oocities.org/dwpennington/C-09.html. Accessed September 1, 2019.

9. Organization for Economic Co-operation and Development (OECD). Adverse outcome pathways, molecular screening and toxicogenomics. http://www.oecd.org/chemicalsafety/testing/adverse-outcomepathways-molecular-screening-and-toxicogenomics.htm. Accessed December 30, 2018.

10. Villeneuve DL, Crump D, Garcia-Reyero N, Hecker M, Hutchinson TH, LaLone CA, et al. Adverse outcome pathway (AOP) development I: strategies and principles. Toxicol Sci 2014;142:312-20.

11. Bond GG, Flores GH, Stafford BA, Olsen GW. Lung cancer and hydrogen chloride exposure: results from a nested case-control study of chemical workers. J Occup Med 1991;33:958-61.

12. Uleckiené $\mathrm{S}$, Griciuté L. Carcinogenicity of sulfuric acid in rats and mice. Pathol Oncol Res 1997;3:38-43.

13. Swenberg JA, Beauchamp RO Jr. A review of the chronic toxicity, carcinogenicity, and possible mechanisms of action of inorganic acid mists in animals. Crit Rev Toxicol 1997;27:253-9.

14. Agency for Toxic Substances and Disease Registry (ATSDR). Toxicological profile for sulfur trioxide and sulfuric acid. https:// www.atsdr.cdc.gov/toxprofiles/tp117.pdf. Accessed September 1, 2019.

15. Shi Q, Maas L, Veith C, Van Schooten FJ, Godschalk RW. Acidic cellular microenvironment modifies carcinogen-induced DNA damage and repair. Arch Toxicol 2017;91:2425-41.

16. National Toxicology Program. NTP 11th Report on Carcinogens. Rep Carcinog 2004:11:1-A32.

17. National Research Council (U.S.). Committee on Toxicology. Emergency and continuous exposure limits for selected airborne contaminants. [Volume 1]. Washington (DC), National Academy Press, 1984.

18. Wisner B, Adams J; World Health Organization (WHO). Environmental health in emergencies and disasters: a practical guide. https://apps. who.int/iris/handle/10665/42561. Accessed September 1, 2019.

19. Kang DS, Yang JH, Kim HS, Koo BK, Lee CM, Ahn YS, et al. Application of the adverse outcome pathway framework to risk assessment for predicting carcinogenicity of chemicals. J Cancer Prev 2018;23:126-33.

20. Organization for Economic Co-operation and Development (OECD). SIDS initial assessment reports for 11th SIAM for sulfuric acid (CAS No: 7664-93-9). http://citeseerx.ist.psu.edu/viewdoc/ download?doi $=10 \cdot 1 \cdot 1.738 .3013 \&$ rep $=$ rep $1 \&$ type $=$ pdf. Accessed September 1, 2019.

21. Browning JA, Wilkins RJ. Mechanisms contributing to intracellular $\mathrm{pH}$ homeostasis in an immortalised human chondrocyte cell line. Comp Biochem Physiol A Mol Integr Physiol 2004;137: 409-18.

22. Leung CY, Palmer LC, Kewalramani S, Qiao B, Stupp SI, Olvera de la Cruz M, et al. Crystalline polymorphism induced by charge regulation in ionic membranes. Proc Natl Acad Sci U S A 2013;110: 16309-14.

23. Capuano P, Capasso G. [The importance of intracellular $\mathrm{pH}$ in the regulation of cell function]. G Ital Nefrol 2003;20:139-50. [Italian]

24. Mimura T, Shindo C, Kato M, Yokota E, Sakano K, Ashihara H, et al. Regulation of cytoplasmic $\mathrm{pH}$ under extreme acid conditions in suspension cultured cells of Catharanthus roseus: a possible role of inorganic phosphate. Plant Cell Physiol 2000;41:424-31.

25. Holma B. Effects of inhaled acids on airway mucus and its consequences for health. Environ Health Perspect 1989;79:109-13.

26. Holma B. Influence of buffer capacity and pH-dependent rheological properties of respiratory mucus on health effects due to acidic pollution. Sci Total Environ 1985;41:101-23.

27. Touzopoulos P, Zarogoulidis P, Mitrakas A, Karanikas M, Milothridis P, Matthaios D, et al. Occupational chemical burns: a 2-year experience in the emergency department. J Multidiscip Healthc 2011;4:349-52.

28. International Programme on Chemical Safety (IPCS). ICSC: 0362 SULFURIC ACID, concentrated ( $>51 \%$ and $<100 \%$ ). http://www. inchem.org/documents/icsc/icsc/eics0362.htm. Accessed September 1, 2019.

29. Treon JF, Dutra FR, Cappel J, Sigmon H, Younker W. Toxicity of sulfuric acid mist. AMA Arch Ind Hyg Occup Med 1950;2:716-34.

30. Cavender FL, Steinhagen WH, Ulrich CE, Busey WM, Cockrell BY, Haseman JK, et al. Effects in rats and guinea pigs of short-term exposures to sulfuric acid mist, ozone, and their combination. J Toxicol Environ Health 1977;3:521-33.

31. Stengel PW, Bendele AM, Cockerham SL, Silbaugh SA. Sulfuric acid induces airway hyperresponsiveness to substance $P$ in the guinea pig. Agents Actions 1993;39 Spec No:C128-31.

32. Morita T, Nagaki T, Fukuda I, Okumura K. Clastogenicity of low $\mathrm{pH}$ to various cultured mammalian cells. Mutat Res 1992;268: 297-305.

33. Chen LC, Fang CP, Qu QS, Fine JM, Schlesinger RB. A novel system for the in vitro exposure of pulmonary cells to acid sulfate aerosols. Fundam Appl Toxicol 1993;20:170-6.

34. Soskolne CL, Pagano G, Cipollaro M, Beaumont JJ, Giordano GG. Epidemiologic and toxicologic evidence for chronic health effects and the underlying biologic mechanisms involved in sub-lethal 
exposures to acidic pollutants. Arch Environ Health 1989;44: $180-91$.

35. Khansari N, Shakiba Y, Mahmoudi M. Chronic inflammation and oxidative stress as a major cause of age-related diseases and cancer. Recent Pat Inflamm Allergy Drug Discov 2009;3:73-80.

36. Langie SA, Koppen G, Desaulniers D, Al-Mulla F, Al-Temaimi R, Amedei A, et al. Causes of genome instability: the effect of low dose chemical exposures in modern society. Carcinogenesis 2015:36 Suppl 1:S61-88.
37. Steenland $\mathrm{K}$. Laryngeal cancer incidence among workers exposed to acid mists (United States). Cancer Causes Control 1997;8:34-8.

38. Li W, Ray RM, Gao DL, Fitzgibbons ED, Seixas NS, Camp JE, et al. Occupational risk factors for nasopharyngeal cancer among female textile workers in Shanghai, China. Occup Environ Med 2006:63:39-44.

39. Cocco P, Ward MH, Dosemeci M. Occupational risk factors for cancer of the gastric cardia. Analysis of death certificates from 24 US states. J Occup Environ Med 1998;40:855-61. 